\title{
Paeoniflorin Improves Cardiac Function and Decreases Adverse Postinfarction Left Ventricular Remodeling in a Rat Model of Acute Myocardial Infarction [Corrigendum]
}

Chen H, Dong Y, He X, Li J, Wang J. Drug Des Devel Ther. 2018;12:823-836.

The authors have advised Figure 11D on page 833 is incorrect. Due to an error at the time of figure assembly
Figure 10D and Figure 11D were duplicated. The correct Figure 11 is shown below.

The authors apologize for this error and advise it does not affect the results of the paper.
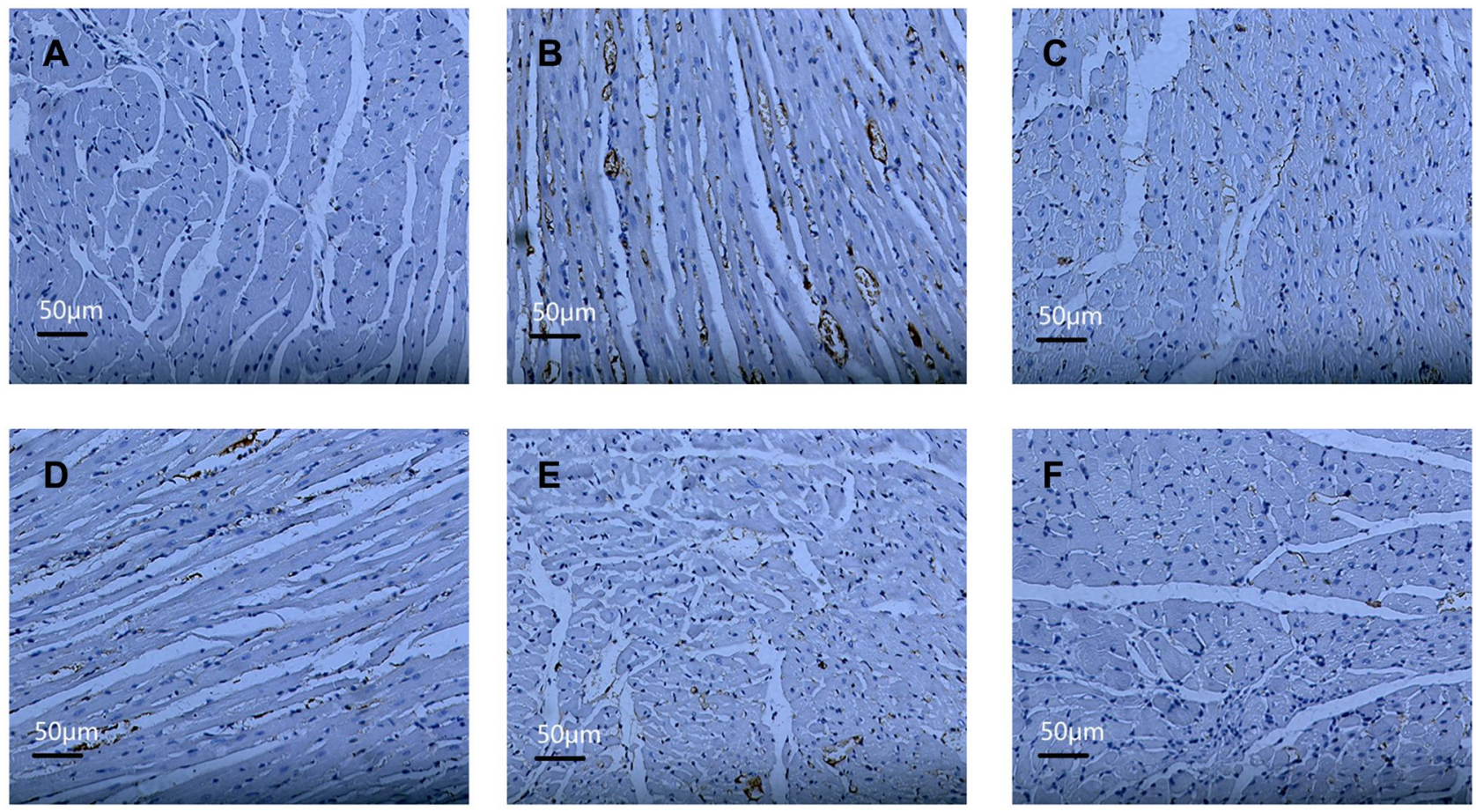

Figure I I Effect of the PF on the expression of Caspase-9 in rats with myocardial infarction (immunohistochemistry, $\times 200$ ).

Note: (A) Sham-operated control, (B) model control, (C) captopril group, (D) low-dose group, (E) middle dose group and (F) high-dose group Abbreviation: PF, paeoniflorin.

\section{Publish your work in this journal}

Drug Design, Development and Therapy is an international, peerreviewed open-access journal that spans the spectrum of drug design and development through to clinical applications. Clinical outcomes, patient safety, and programs for the development and effective, safe, and sustained use of medicines are a feature of the journal, which has also been accepted for indexing on PubMed Central. The manuscript management system is completely online and includes a very quick and fair peer-review system, which is all easy to use. Visit http://www. dovepress.com/testimonials.php to read real quotes from published authors. 